DOCTRINA

\title{
La tipificación de los delitos de injuria y calumnia y su efecto inhibitorio en el ejercicio de la libertad de expresión en Chile
}

\author{
Establishing of criminal offences of libel and slander and their inhibitory effect \\ on the exercise of freedom of expression in Chile
}

\author{
Pablo Viollier \\ Derechos Digitales, Chile
}

Matías Salinas

Corte de Apelaciones de San Miguel, Chile

\begin{abstract}
RESUMEN Este artículo analiza el efecto inhibitorio que la tipificación del delito de injuria y calumnia tiene en el ejercicio de libertad de expresión en nuestro país. El rol central que cumple la libertad de expresión en una sociedad democrática contrasta con la deficiente compatibilización que estos tipos penales hacen entre la protección de la honra de las personas - en especial de las figuras públicas- y el legítimo ejercicio de la libertad de expresión. De esta forma, la utilización estratégica de estos tipos penales las ha transformado en verdaderas instituciones inhibidoras del ejercicio del derecho a informar y, por consiguiente, a ser informado.
\end{abstract}

PALABRAS CLAVE Libertad de expresión, derecho a la honra, derechos humanos, efecto inhibitorio.

ABSTRACT This article analyzes the inhibitory effect that the definition of criminal offences of libel and slander has on the exercise of freedom of expression in our country. The central role that freedom of expression fulfills in a democratic society contrasts with the deficient compatibility that these criminal types make between the protection of reputation - specially of public persons - and the legitimate exercise of free speech. In this way, the strategic treatment of these criminal offenses has transformed them into true institutions that inhibit the exercise of the right to inform and therefore to be informed.

KEYWORDS Freedom of expression, right to honor, human rights, inhibitory effect. 


\section{Introducción}

En nuestro país, el derecho a la libertad de expresión se encuentra consagrado a nivel legal y constitucional. A partir de la lectura de los tratados internacionales firmados y ratificados por Chile, como la Declaración Universal de los Derechos Humanos, la Convención Americana de Derechos Humanos y el Pacto sobre Derechos Civiles y Políticos, podemos definir el derecho a la libertad de expresión como la libertad de emitir, difundir, buscar y recibir opiniones, ideas e información, bajo cualquier medio de expresión y sin limitaciones de fronteras con la seguridad de no ser perturbado por ello.

En los Estados democráticos toma especial importancia la capacidad de expresarse por parte de los ciudadanos en general, y el ejercicio del periodismo en particular, no solo porque a través de ellos se concreta la fiscalización al quehacer de los funcionarios públicos, sino porque garantiza el pleno goce y ejercicio del derecho a la libertad de expresión, que se manifiesta en la posibilidad de informar y ser informado.

A pesar de existir esta protección legal y constitucional, el ejercicio del derecho a la libertad de expresión puede verse perturbado por prácticas que se han instalado en la cultura política nacional, como la interposición de querellas de forma abusiva y estratégica por parte de quienes se sientan aludidos ante la publicación de un reportaje de investigación, columna de opinión u otra forma de expresión. ${ }^{1}$

La finalidad del presente artículo es dar cuenta de cómo el abuso de tipos penales presentes en nuestro sistema jurídico, en especial los delitos de injurias y calumnias, se ha transformado en un impedimento no solo de carácter jurídico, sino que también fáctico para el ejercicio de la libertad de expresión, al producir un efecto inhibitorio en la capacidad de las personas para expresarse libremente y buscar la información por los medios que mejor estimen convenientes. Para ello, haremos una revisión bibliográfica respecto de los alcances de la libertad de expresión en nuestro ordenamiento jurídico, así como la noción e implicaciones de la figura del efecto inhibitorio. Este análisis se complementa con un estudio de casos particulares en los cuales la utilización de las figuras de la injuria y la calumnia han sido utilizadas con el efecto de obstaculizar el ejercicio del periodismo.

En la primera sección de este trabajo nos proponemos dar cuenta sucintamente de la regulación vigente en materia de libertad de expresión, su relación con la democracia y el ejercicio del periodismo. La segunda sección está dedicada a la legislación

1. Entre los años 2010 y 2016 se triplicaron los casos de injurias y calumnias por medios de comunicación tramitados ante tribunales. Esta cifra se elevó de 173 casos en 2010 a 532 en 2015. De un total de 2.456 causas tramitadas en este periodo, solo 47 terminaron en sentencia condenatoria, cerca del $2 \%$. El resto de los procesos terminaron con 252 absoluciones y 932 sobreseimientos definitivos. Véase Andrés López y Carlos Reyes, "Casos de injurias fallados por los tribunales se triplican en seis años», La Tercera, 29 de diciembre de 2016, disponible en http://bit.ly/2XwBCNo. 
nacional vigente, con especial énfasis en la tipificación de los delitos de injurias y calumnias, haciendo alusión a sus alcances, excepciones y los bienes jurídicos que se buscan proteger, en especial la honra de las personas. La tercera sección analiza la figura del efecto inhibitorio a nivel doctrinario y analiza cómo la tipificación de la injuria y la calumnia en Chile puede producir este efecto, al generar una protección desproporcionada del derecho a la honra en desmedro del derecho a la libertad de expresión. Por último, se entregan conclusiones preliminares y recomendaciones de modificación legislativa.

\section{Libertad de expresión: Algunos alcances}

Nuestra Constitución, en su artículo 19, numeral 12, inciso primero, asegura a todas las personas: «La libertad de emitir opinión y la de informar, sin censura previa, en cualquier forma y por cualquier medio, sin perjuicio de responder de los delitos y abusos que se cometan en el ejercicio de estas libertades, en conformidad a la ley, la que deberá ser de quórum calificado». Esta disposición, redactada en línea con las obligaciones internacionales de derechos humanos de Chile, asegura que toda persona puede ejercer el derecho a informar y a ser informado sin miedo a represalias posteriores, sin importar el lugar y el medio utilizado. Sin embargo, la misma regulación constitucional indica ciertos límites al ejercicio y goce de este derecho.

Los límites antes señalados pueden ser intrínsecos o extrínsecos: los primeros son aquéllos que se derivan de la propia naturaleza del derecho, mientras que los extrínsecos derivan de límites impuestos por otros derechos fundamentales. Lo anterior puede generar conflictos con otros derechos fundamentales, en los que corresponderá al legislador o al juez, según proceda, la obligación de ponderar cómo armonizar los derechos fundamentales en juego, procurando mantener la esencia de cada derecho.

A pesar de que nuestra Constitución se exprese solamente en términos de «emitir opinión» e «informar», es importante establecer que el derecho a la libertad de expresión está formado por la dualidad indisoluble de expresar (derecho a informar) y de ser informado (derecho a la información). Estas facetas se encuentran una en función de la otra recíprocamente, ya que el ejercicio pleno de este derecho depende copulativamente de ambas. ${ }^{2}$

El Tribunal Constitucional ha dictaminado que «si bien en la letra de la Ley Fun-

2. Para efectos de este artículo nos enfocaremos en estos dos aspectos del ejercicio de la libertad de expresión. Sin embargo, es importante notar que la literatura ha desarrollado extensamente que libertad de expresión también cumple un rol importante en otros aspectos, como la habilitación de la participación al interior del Estado democrático (Vega Zamora, 2012), la libertad de pensamiento (Ansuátegui, 1992), la libertad personal y garantía de la autonomía individual (Nieves, 2016) y de la autodeterminación colectiva (OEA, 2009). 
damental no aparece consagrado expresamente el derecho a recibir informaciones, éste forma parte natural y se encuentra implícito en la libertad de opinión y de informar, porque de nada sirven estas libertades si ellas no tienen destinatarios reales». ${ }^{3}$

La naturaleza indisoluble de ambas funciones tiene como consecuencia múltiples aristas y manifestaciones, lo que amplía considerablemente las formas en las cuales puede ser vulnerado. Cualquier acto o conducta que esté destinado a entorpecer la entrega de información, la búsqueda de información y la libre elección de los medios con los cuales informarse, puede configurarse como un elemento atentatorio contra la libertad de expresión. De esta forma, la doctrina ha señalado que el derecho a informarse

obliga a los Estados y sus órganos y organismos a no realizar actos y conductas u omisiones destinadas a evitar o limitar la libre recepción de la información de carácter público, de relevancia pública o destinada al público, como asimismo, el deber de promover las condiciones que posibiliten su pleno ejercicio, eliminando los obstáculos o trabas factuales, jurídicas o conductuales que afecten o entorpezcan a través de limitaciones, controles o formalidades desproporcionadas o irrazonables a la recepción de la información (Nogueira Alcalá, 2002: 35).

$\mathrm{Al}$ respecto, la Corte Interamericana de Derechos Humanos ha expresado que

La libertad de expresión es una piedra angular en la existencia misma de una sociedad democrática. Es indispensable para la formación de la opinión pública. Es también conditio sine qua non para que los partidos políticos, los sindicatos, las sociedades científicas y culturales, y en general, quienes deseen influir sobre la colectividad puedan desarrollarse plenamente. Es, en fin, condición para que la comunidad, a la hora de ejercer sus opciones, esté suficientemente informada. Por ende, es posible afirmar que una sociedad que no está bien informada no es plenamente libre. ${ }^{4}$

En el ejercicio del periodismo se aprecia con mayor notoriedad la estrecha relación entre el derecho a informar y a ser informado, transformando a los periodistas en intermediarios entre el mundo político y la ciudadanía; al ejercer una función pública de fiscalización que solo puede ser garantizada bajo un libre ejercicio de la profesión, que al ejercer el derecho a informar se transforma - para la ciudadaníaen el derecho a la información por el cual se genera la opinión pública. Como señala Gandolfo:

El periodismo que, visto desde el derecho a la información, se convierte en «función pública», «servicio público», «responsabilidad social»o «deber de informar»,

3. Sentencia del Tribunal Constitucional, rol 226, 21 de noviembre de 1997, considerando 19.

4. Corte Interamericana de Derechos Humanos, Opinión Consultiva OC-5/85, 1985. 
analizado, en cambio, en la perspectiva de la libertad de información es una simple manifestación o ejercicio que un individuo hace generalmente de la misma de modo habitual y asalariado. Lo que está en juego, primaria y principalmente, en el periodismo es, pues, la libertad de información, la que, como se dijo, es una de las modalidades de la libertad de expresión (Gandolfo, 1994: 274).

\section{Legislación nacional vigente}

A través de un estudio del ordenamiento jurídico chileno, resulta posible evidenciar una primacía del derecho a la honra en contraposición al derecho a la libertad de expresión, toda vez que el primero se protege de manera desproporcionada en detrimento del segundo.

La justificación para esta limitación al ejercicio de la libertad de expresión está relacionada, como ya vimos, con la colisión que puede generarse respecto de otros derechos fundamentales, como el respeto y protección a la vida privada y a la honra. Normativamente, estos derechos están protegidos por la Constitución Política de la República, la cual en su artículo 19 numeral 4 asegura «el respeto y protección a la vida privada y a la honra de la persona y su familia».

Con la reforma constitucional del 2005, dicho artículo fue modificado, derogando la figura de difamación criminal que se encontraba en el inciso segundo, la cual había sido incluida por sugerencia del Consejo de Estado. Las palabras del consejero Jorge Alessandri en sesión 60, del 26 de diciembre de 1978, ilustran el sentir del Conejo. Según Alessandri, «el concepto de libertad de prensa, tal como emanó de los postulados de la Revolución francesa, es hoy algo obsoleto y cuya vigencia resulta incompatible con el gobierno de los pueblos y con la tranquilidad pública» (Charney, 2016: 178).

\section{El delito de injurias}

El artículo 416 del Código Penal define de forma amplia el delito de injuria como «toda expresión proferida o acción ejecutada en deshonra, descrédito o menosprecio de otra persona». Para la mayoría de la doctrina, los elementos que configuran el tipo penal son dos: un elemento objetivo y uno subjetivo. El primero consiste en la necesidad de una exteriorización que puede ser hecha de dos formas según el legislador: a través de la expresión y la acción. La expresión se refiere solamente a la palabra hablada, mientras que la acción se refiere a cualquier medio o sistema por el cual podamos exteriorizar una opinión — excluyendo la palabra hablada - como pueden ser gestos, movimientos, dibujos, montajes fotográficos, etcétera, incluida la palabra escrita, la cual el legislador se preocupó de desarrollar en el artículo 422 del mismo cuerpo legal, debido a su importancia. Este primer elemento es de naturaleza objetiva. 
El segundo elemento, de carácter subjetivo, está determinado por la finalidad de la expresión o la acción incurrida; la que debe estar dirigida con la intención de lesionar el honor y la dignidad de una persona. La doctrina se encuentra dividida respecto de si la concurrencia de este elemento (denominado animus injuriandi) es necesario para que se den los presupuestos del delito de injurias. Este elemento subjetivo es entendido como «una voluntad de causar un daño al ofendido, diverso al dolo, que involucra el conocimiento que la acción o expresión es objetivamente agraviante para la víctima» (Garrido Montt, 1998: 203).

La Corte Suprema ha dicho al respecto que «para que se configure el delito de injuria no solo es menester que exista la voluntad de ejecutar los actos o de proferir las expresiones injuriosas, sino el ánimo de ofender (animus injuriandi)».5 Acreditar este ánimo o intención debe ser probado ante los tribunales. Este elemento subjetivo va en conjunto con el dolo requerido para que el delito sea imputable. En principio, para el tipo penal es indiferente la veracidad o falsedad de la expresión, bastando que sea ejecutada en deshonra, descrédito o menosprecio de otra persona para que el delito quede configurado.

\section{El delito de calumnias}

El Código Penal, en su artículo 412, define el delito de calumnias como la imputación de un delito determinado pero falso y que pueda actualmente perseguirse de oficio. En palabras simples, consiste en atribuirle a una persona un delito que no cometió, exigiendo que dicho delito sea de aquéllos que la justicia puede perseguir de oficio.

El elemento objetivo del delito de calumnias es el mismo que se analizó en el apartado anterior para el delito de injurias, salvo que existe una exigencia de determinación de dicho mensaje. Para ello es necesario que: i) la imputación del delito sea de un delito determinado; ii) el delito imputado sea falso, en el sentido de su materialidad o respecto de la autoría de la persona a la cual se le imputa; y iii) el delito imputado sea actualmente perseguible de oficio.

Respecto del elemento subjetivo del delito de calumnias, al igual que el delito de injurias requiere dolo para su comisión, pero para la mayoría de la doctrina nacional se excluye el doble requisito subjetivo negando la necesidad de un animus infamandi, como señala Garrido Montt:

El dolo en la calumnia debe estar integrado por el conocimiento de la falsedad objetiva de imputación, el actor sabe que el delito no se ha cometido o que carece de antecedentes verosímiles de su comisión o habiéndose cometido, que el agraviado no tiene responsabilidad en él. Subjetivamente la imputación tiene que ser falsa, el sujeto activo ha de estar al tanto de la mendacidad de sus afirmaciones (Garrido Montt, 1998: 173).

5. Corte Suprema, 20 de abril de 1954, citado por Labatut Glena (1977: 200). 


\section{El efecto inhibitorio de la tipificación penal de la injuria y la calumnia en el ejercicio del periodismo}

Un aspecto menos explorado por la doctrina nacional, y recogido de forma deficitaria por la legislación, es que al ser la libertad de expresión un valor afirmativo, ${ }^{6}$ su limitación no solo constituye una vulneración individual del derecho del agente en cuestión, sino una vulneración del derecho de los miembros de la sociedad en su conjunto para buscar y recibir información por cualquier medio de su elección. De este modo, la existencia de una consagración formal del derecho a la libertad de expresión de poco vale si no existe un ambiente propicio para que la discusión de temas públicos, la expresión de nuevas opiniones o el intercambio de ideas se ejerza sin el temor a represalias judiciales. En este caso, no solo se produce una vulneración del derecho a la libertad de expresión de la población, sino también una pérdida social sensible, toda vez que la protección del discurso resulta indispensable para la vitalidad del sistema democrático (Charney, 2016: 176).

Distintos organismos internacionales se han pronunciado respecto al efecto que la tipificación de los delitos de injuria y la calumnia produce en el ejercicio de la libertad de expresión, tanto a nivel comparado como en nuestro país. En su jurisprudencia, la Comisión Interamericana de Derechos Humanos ha señalado que este tipo de sanciones «no solo impiden que las personas conozcan informaciones relevantes para el ejercicio de sus derechos, sino que generan un efecto intimidatorio que contradice la obligación del Estado de establecer un marco institucional en el cual el debate sobre todos los asuntos públicos pueda ser abierto, plural, desinhibido y vigoroso»?

Del mismo modo, la Relatoría Especial para la Libertad de Expresión del mismo organismo, en su informe anual publicado en marzo de 2017, se refirió específicamente a nuestro país al señalar que «estas figuras penales siguen siendo utilizadas para someter a juicio a periodistas por discursos que afectarían el honor y reputación de funcionarios públicos y funcionarios que ocupan cargos electivos, con el consiguiente efecto de inhibir y restringir la investigación y difusión de información de interés público» (CIDH, 2017: 378).

El mismo informe también mostró preocupación por la por la condena a 540 días de reclusión menor en su grado mínimo, en conjunto con una multa y la suspensión para ejercer cargos públicos que sufrieron dos periodistas del medio El Ciudadano ante la querella presentada por injurias graves por parte de un diputado de la República. Esta sanción, confirmada por la Corte Suprema, ${ }^{8}$ tuvo como fundamento que

6. Esto implica que, como sociedad, resulta igual de importante el fomentar la libertad de expresión que limitar la capacidad del poder político para restringirla (Schauer, 1978: 691).

7. Caso, Jorge Fonteveccia y Héctor D’Amico con Argentina, Comisión Interamericana de Derechos Humanos, informe 82/10, caso 12.524, 13 de julio 2010, párrafo 111, disponible en http://bit.ly/2xGKWyB.

8. Corte Suprema de Chile, causal rol 1310027365-3, 11 de junio de 2015. 
los imputados no fueron capaces de aportar antecedentes precisos, claros, concretos y verificables para dar por establecido que tuvieron el debido cuidado al momento de verificar la veracidad de la información que publicaron.

Otro caso recogido por el informe de la Relatoría, a pesar de que no tuvo una resolución judicial, fue la presentación de una querella por el delito de injurias graves contra cuatro periodistas de la revista Qué Pasa por la entonces presidenta de la República Michelle Bachelet. La querella, presentada el 31 de mayo de 2016, solicitaba la condena por tres años de prisión para los denunciados debido a la publicación de una nota que reproducía una interceptación telefónica de uno de los imputados en el caso Caval, y tenía el fin declarado el exigir «la ética y la responsabilidad que deben tener los medios a la hora de informar validando las fuentes» (CIDH, 2017: 378).

A pesar de que la entonces presidenta anunció haber presentado la querella en su «calidad de ciudadana», ${ }^{9}$ las reacciones no se hicieron esperar. En este sentido, la entonces directora del Instituto Nacional de Derechos Humanos, Lorena Fries, señaló que «responsabilizar a los medios sobre una afectación a un derecho humano como es la honra lo que se ha establecido en términos de estándares no es la vía penal, es la vía civil». ${ }^{10}$

Ante la presentación de la querella, la revista Qué Pasa bajó la versión digital del artículo en cuestión, ${ }^{11}$ pero rechazó la presentación de la querella criminal en contra de sus empleados, señalando que «el hecho que la querella sea presentada por la presidenta en calidad de ciudadana no disminuye esta presión, ya que ambas calidades son inseparables». ${ }^{12}$ Finalmente, la querella fue retirada el 30 de septiembre de 2016 por el gobierno, ${ }^{13}$ luego de que el Consejo de Ética de los Medios de Comunicación Social de Chile de la Federación de Medios de Comunicación sancionara a la revista Qué Pasa por el artículo en cuestión, señalando que es

deber del medio de comunicación evaluar las declaraciones que obtenga de su trabajo periodístico tanto desde la perspectiva de la credibilidad de las fuentes así como del necesario contraste de los juicios y valoraciones efectuados con terceras personas (CIDH, 2017: 372).

9. Constanza Saez, «Abogados por querella de la presidenta: "A ella no le corresponde definir qué es el periodismo serio"», Radio Universidad de Chile, 1 de junio de 2016, disponible en http://bit.ly/2xMpmbO.

10. R. Álvarez, «INDH rechaza querella de Bachelet contra revista Qué Pasa: "Hay una colisión de derechos"», La Tercera, 2 de junio de 2016, disponible en http://bit.ly/2xGAHKE (citado en CIDH, 2017).

11. «Revista Qué Pasa baja nota con grabaciones alusivas a la presidenta y Bachelet habla de "canallada"», El Mostrador, 27 de mayo de 2016, disponible en http://bit.ly/2xKQjg8 (citado en CIDH, 2017).

12. «Declaración de revista Qué Pasa ante querella de presidenta Bachelet», Qué Pasa, 31 de mayo de 2016, disponible en http://bit.ly/2xLqxIA (citado en CIDH, 2017).

13. «Bachelet retira querella contra revista Qué Pasa tras sanción ética de Consejo de Medios», Emol, 30 de septiembre de 2016, disponible en http://bit.ly/2xLqPza (citado en CIDH, 2017). 
Sin embargo, el episodio es recordado como la primera vez desde la vuelta a la democracia en que un presidente de la República ha buscado encarcelar a un periodista utilizando este tipo penal.

Por último, la utilización de estas figuras penales por parte de personalidades públicas con el fin de inhibir la labor de la prensa le valió a Chile, en parte, una caída de cinco puestos en el índice de libertad de expresión de la organización Reporteros Sin Fronteras. Chile pasó del puesto 33 en 2017 al puesto 38 en el 2018. Esta caída se justificó por el alto nivel de concentración económica de los medios en Chile, el cierre de varias radios comunitarias, así como porque «varios periodistas que estaban investigando casos de corrupción que implicaban a funcionarios y asociados de la expresidenta Michelle Bachelet fueron objeto de demandas arbitrarias por difamación».14

Con el fin de dar cuenta de esta doble vulneración producida por la tipificación penal del delito de injuria y calumnia, resulta útil echar mano a la doctrina jurídica anglosajona del chilling effect o efecto inhibitorio; doctrina que se ha transformado en un importante componente sustantivo de la adjudicación judicial en materia de libertad de expresión en Estados Unidos. ${ }^{15}$

\section{Definición del efecto inhibitorio}

Según el constitucionalista estadounidense especialista en libertad de expresión Frederick Schauer, el efecto inhibitorio tiene lugar cuando «individuos que buscan realizar alguna actividad protegida por la primera enmienda son disuadidos de realizar dicha actividad por alguna regulación gubernamental que no está específicamente dirigida a dicha actividad protegida» (Schauer, 1978: 693). De esta definición es posible dar cuenta de tres elementos distintivos del efecto inhibitorio, que lo diferencian de otras formas de vulneración de la libertad de expresión.

La primera característica particular del efecto inhibitorio es que constituye, en esencia, un acto de disuasión. De esta forma, el daño del efecto inhibitorio se produce cuando algo que puede y debe ser expresado, deja de ser expresado. El individuo

14. «Chile», Reporteros Sin Fronteras, 2018, disponible en https://rsf.org/en/chile (la traducción es nuestra).

15. Sin embargo, a fin de hacer una comparación rigurosa, es importante dar cuenta de una diferencia importante entre nuestro ordenamiento jurídico y el estadounidense. La aproximación estadounidense a la doctrina del efecto inhibitorio opera bajo la premisa de que la libertad de expresión constituye un «valor trascendente», y, por tanto, que un error en la limitación de la libertad de expresión es socialmente más grave que un error en la sobreextensión del mismo derecho (véase Cahn, 1956; citado en Schauer, 1978: 688). Por el contrario, como es posible dar cuenta al analizar los delitos de injuria y calumnia, nuestra legislación no solo no entrega una preferencia a priori a la libertad de expresión, sino que hace una insuficiente ponderación de derechos, otorgando una protección desproporciona a la honra de las personas, en detrimento del ejercicio de la libertad de expresión. 
es disuadido de publicar algo que puede y debe expresar, por miedo a un castigo ulterior. Esta situación no solo es peligrosa por el daño que produce el hecho de que un derecho constitucional legítimo deja de ser ejercido, sino por el daño social que produce el empobrecimiento del debate público y el intercambio de ideas por la falta de dicho ejercicio.

La segunda característica es que la actividad respecto de la cual es individuo es disuadido de hacer debe estar amparada por el derecho constitucional a la libertad de expresión. En efecto, hasta el momento hemos utilizado la palabra disuasión en su acepción peyorativa, pero es fácil dar cuenta cómo el objetivo de una parte importante de la legislación es disuadir a los individuos de incurrir en ciertas conductas. De esta forma, las penas establecidas en la ley de tránsito tienen como objetivo disuadir a los individuos de hacer acciones imprudentes al volante, la Ley del Consumidor busca sancionar a las empresas que busquen aprovecharse de la relación asimétrica con sus compradores, y un largo etcétera (Politoff, Matus y Ramírez, 2003: 59). De esta forma, solo estaremos ante un efecto inhibitorio cuando la regulación logre disuadir al afectado de ejecutar una actividad que legítimamente está habilitado de ejecutar bajo el amparo del derecho a la libertad de expresión.

Por último, el efecto inhibitorio solo tendrá valor como herramienta de análisis en la medida de que se trate de una limitación indirecta de la libertad de expresión. En relación con el apartado anterior, el efecto inhibitorio solo se producirá en la medida en que el individuo se vea disuadido de hacer cierta conducta, y no derechamente impedido. En caso de limitación directa, la doctrina del efecto inhibitorio no agrega nada de valor al análisis. De este modo, la prohibición del discurso de odio no produce un efecto inhibitorio en esta materia, en la medida en que derechamente impide la propagación de cierto tipo de discurso.

Para estar en presencia de un efecto inhibitorio debe tratarse de alguna regulación gubernamental que no está específicamente dirigida a una actividad protegida por la libertad de expresión, pero que produce el efecto de que los individuos se abstengan de ejercer su legítimo derecho en base a un razonable miedo a eventuales represalias. En este sentido, la vulneración de la libertad de expresión no es un objetivo activamente buscado por la tipificación de la injuria y la calumnia, sino más bien una externalidad negativa producida por una excesiva protección del derecho a la honra de los individuos en desmedro del ejercicio de la libertad de expresión.

\section{La tipificación de la injuria y la calumnia como protección desproporcionada de la honra en detrimento de la libertad de expresión}

El derecho a la honra se encuentra recogido en el artículo 19 número 4 de nuestra Carta Fundamental, la que se limita a expresar que la Constitución asegura a todas las personas «el respeto y protección a la vida privada y a la honra de la persona y su fa- 
milia». La doctrina, por su parte, ha señalado que el derecho a la protección de honra constituye una facultad que emana de la dignidad humana y de su realidad inserta en la sociedad, y distingue entre dos dimensiones del derecho: la heteroestima, entendida como el aprecio de los demás por nuestros actos y comportamientos; y la autoestima, como consciencia de la autenticidad de accionar persona en su comportamiento societal (Nogueira, 2003: 245). Por su parte, la jurisprudencia de la Corte Suprema de Chile da cuenta de dicha distinción reconociendo la existencia de un alcance objetivo - referido a la apreciación de terceros- y uno subjetivo, relativo a la estimación propia o interna. Sin embargo, solo reconoce relevancia jurídica al alcance objetivo. ${ }^{16}$

Todo sistema jurídico que busque asegurar derechos a sus ciudadanos requiere que dichos derechos sean reconocidos y consagrados a través de una correcta delimitación de su contenido en base a su relación con otros derechos de la misma jerarquía constitucional (Nogueira, 2003: 245).

En este sentido, como ha señalado Nogueira (2004: 141):

Los límites de cada derecho se establecen en contraste con los demás derechos y bienes constitucionalmente protegidos, a la luz de las circunstancias de cada caso concreto. Todos los derechos deben ser respetados en su contenido y dentro de sus límites, debiendo realizarse un esfuerzo interpretativo de compatibilización o de armonización, evitándose la posición cómoda de aniquilar el ejercicio de un derecho en beneficio de otro.

Esta correcta ponderación entre derechos de la misma jerarquía constitucional -derecho a la honra y la libertad de expresión- es la que se encuentra ausente en la tipificación de la injuria y la calumnia, que resguarda con excesivo celo el primer derecho en detrimento del segundo. La consecuencia de esta deficiente tipificación es que, en distintas circunstancias de la vida social, los individuos pueden verse disuadidos de expresar informaciones y opiniones legítimas y amparadas por la libertad de expresión, por miedo a ser víctimas de una persecución penal.

A continuación $-\mathrm{y}$ siguiendo las pautas ofrecidas por Nogueira-, se ofrece una somera descripción de cómo la tipificación de la injuria y la calumnia habilitan la generación de un efecto inhibitorio al momento de ejercer el derecho a la libertad de expresión.

La excesiva limitación de la exceptio veritatis en los delitos contra el honor de las personas

La exceptio veritatis o excepción de verdad es la exención de responsabilidad penal de la parte querellada por el hecho de probar la veracidad de sus dichos. En nuestra le-

16. Sentencia de la Corte Suprema, rol 8.140-2009, 19 de enero de 2010 (citado en Fuentes, 2011: 552). 
gislación penal es la regla general en el caso del delito de calumnia, quedando exento de responsabilidad penal el que pueda probar el hecho criminal que le imputó a un tercero. ${ }^{17}$ El problema se da respecto al delito de injurias, en el cual la exceptio veritatis está legislada solo como una excepción, teniendo cabida respecto de situaciones que guarden estricta relación con el interés público. Esta excepción se encuentra consagrada en el artículo 420 del Código Penal, en los siguientes términos: «Al acusado de injuria no se admitirá prueba sobre la verdad de las imputaciones, sino cuando éstas fueren dirigidas contra empleados públicos sobre hechos concernientes al ejercicio de su cargo».

De esta forma, el legislador reconoce, de forma limitada, la importancia que tiene poder fiscalizar a los empleados públicos en una sociedad democrática. En razón de aquello, establece la exceptio veritatis para los casos antes descritos.

Esta excepción del artículo 420 del Código Penal se ve reforzada por el artículo 30 de la Ley 19.773 sobre Libertades de Opinión e Información y Ejercicio del Periodismo, conocida como la ley de prensa, que establece la exceptio veritatis en favor del acusado por injurias cuando su publicación fue hecha «con motivo de defender un interés público real».

A pesar de que la exceptio veritatis es una protección a la libertad de informar, no es garantía suficiente para resolver la tensión producida con otros derechos fundamentales. El primer problema es que la ley de prensa solo es aplicable cuando las opiniones sean hechas en un medio de comunicación social, por ende, si el acto que se estima injurioso es hecho en la vía pública, en una concentración política o una manifestación, el inculpado solo tendría la protección del artículo 420 del Código Penal, con todas las limitantes antes analizadas.

Para Charney, el legislador entra en una contradicción. Si lo que se quiere proteger es el honor de la persona, objetivamente el honor se verá afectado si la publicación injuriosa es verdadera o es falsa,

por ello, el daño objetivo a la honra de una persona a causa de una expresión injuriosa aumenta considerablemente si esta expresión es proferida por un medio de comunicación social. Esto indica que, si la excepción de la verdad ampara expresiones injuriosas transmitidas en los medios de comunicación social, también debiera amparar las mismas expresiones cuando éstas no sean enunciadas por estos medios (Charney, 2016: 184).

En efecto, no existe una razón que fundamente permitir a quienes publiquen en medios de comunicación justificar sus expresiones a través de la exceptio veritatis, pero que excluya al resto de los ciudadanos de esgrimir la misma excepción excul-

17. El artículo 415 del Código Penal establece que «El acusado de calumnia quedará exento de toda pena probando el hecho criminal que hubiere imputado». 
pante. Especialmente si se tiene en consideración que se trata de otros ámbitos de la vida social, en los que la expresión de ideas y opiniones también cuenta con el amparo del derecho a la libertad de expresión, como conferencias académicas, manifestaciones sociales, expresiones emitidas en redes sociales $u$ otras circunstancias de la vida social.

\section{Los límites de la crítica permitida son más amplios respecto de una persona de relevancia pública en las actuaciones correspondientes a sus funciones}

Los personajes o figuras públicas son aquellos individuos ampliamente reconocidos en la sociedad por su fama o notoriedad pública. El carácter de personaje o figura pública no solo alcanza a quienes ejercen cargos de autoridad pública, sino que también a los que voluntariamente se hacen parte de acontecimientos de relevancia pública. ${ }^{18}$

Son estas dos circunstancias - el hecho de ejercer un cargo de autoridad o de voluntariamente hacerse parte de cuestiones de relevancia pública- las que justifican que dichos individuos deban soportar un nivel mayor de críticas por parte de la colectividad sobre su persona (Doherty, 2007). Como contrapartida, esta exposición mayor a la crítica solo puede referirse a las funciones de autoridad o a los hechos de relevancia pública en que voluntariamente se haya involucrado la figura pública, y no podrá extenderse a circunstancias de carácter personal que no constituyan actos, hechos o datos de relevancia pública (Covarrubias Cuevas, 2015).

Sin embargo, la tipificación de la injuria hace dicha distinción de forma deficitaria. En efecto, el artículo 420 del Código Penal establece que «al acusado de injuria no se admitirá prueba sobre la verdad de las imputaciones, sino cuando éstas fueren dirigidas contra empleados públicos sobre hechos concernientes al ejercicio de su cargo» (el énfasis es nuestro).

En definitiva, la exceptio veritatis, respecto de la cual se profundizará a continuación, solo es admitida respecto de ciertas figuras públicas: ${ }^{19}$ los empleados públicos. Sin embargo, existe una multiplicidad de figuras públicas que están sometidas a un nivel mayor de crítica pública por la posición que cumplen en la sociedad, a pesar de no ser empleadas públicas. De esta forma, un individuo no podrá hacer uso de la

18. Caso Curtis Publishing Co. con Butts, Corte Suprema de Estados Unidos, 388 U.S. 130, 164 (1967); Gertz con Robert Welch, 418 U.S. 323, 344, 363 (1974): «Quienes deciden participar en la esfera pública asumen voluntariamente la reducción de su vida privada en comparación con quienes permanecen en el anonimato» $\mathrm{y}$ «los personajes públicos tienen mayor acceso de para enfrentar a la prensa o para contrarrestar la información perjudicial» (citado en Covarrubias Cuevas, 2015).

19. El empleo del término «figura pública» tampoco es particularmente feliz, toda vez que existe un número importante de funcionarios públicos que no son figuras públicas por su nivel de exposición pública, y sin embargo deben soportar una intrusión mayor en su vida privada como consecuencia de su función (Covarrubias Cuevas, 2005). 
excepción contenida en el artículo 420 del Código Penal cuando las imputaciones se refieren a figuras públicas como miembros de partidos políticos que no sean empleados públicos, intelectuales, académicos, deportistas, líderes de opinión u otros.

De este modo, al momento de expresar una opinión o dar cuenta de un hecho relativo a una figura pública que es no es funcionario público, penderá sobre el individuo un nivel mayor de riesgo de ser perseguido penalmente por el afectado, ya que no podrá zafar de la persecución criminal probando la verdad de sus alegaciones.

Esta limitación se ve atenuada por lo establecido en el artículo 30 de la Ley 19.773 sobre Libertades de Opinión e Información y Ejercicio del Periodismo, la que al igual que en el caso del interés público real admite la exceptio veritatis en un sentido más amplio que el artículo 420 del Código Penal, extendiéndose a cuando el afectado ejerciere funciones públicas (en un sentido más amplio) y la imputación se refiere a hechos propios de tal ejercicio. Sin embargo, dicha protección solo se hace efectiva cuando la supuesta injuria se haya comunicado a través de un medio de comunicación social.

\section{La inversión de la carga de la prueba en perjuicio de la libertad de expresión}

Por último, la invocación de la exceptio veritatis se ve dificultada por la inversión en la carga de la prueba establecida en la legislación, toda vez que el legislador ha entregado la carga de la prueba en esta situación al querellado.

La razón para establecer de tal forma la carga de la prueba es para que el emisor del mensaje verifique la veracidad de éste o de los hechos antes de divulgarlos, previniendo de esta forma hacer una publicación de carácter injurioso. Nuevamente, es posible verificar que la tipificación opta por una protección desproporcionada de la honra del afectado en detrimento de la libertad de expresión.

El problema de la carga de la prueba radica en que probar la verdad nunca ha sido fácil, en especial porque, generalmente, quien tiene los medios para probar la veracidad de dichas alegaciones es el querellante. La prueba de la verdad, o mejor dicho la dificultad de probar la verdad, se transforma en un hecho de carácter disuasivo, que propende a que los agentes se abstengan de informar o publicar sobre un hecho a pesar de que éstos sean verdaderos, solo por el hecho de no contar con los medios suficientes de prueba. En este sentido, la necesidad de probar algo ante tribunales no solo requiere de un nivel de rigurosidad al momento de recabar y comunicar la información, sino también de la capacidad económica de producir evidencia e introducirla a través de un abogado calificado.

Respecto de este punto, el caso The New York Times con Sullivan, ${ }^{20}$ fallado por la

20. Caso New York Times Co. con Sullivan, Corte Suprema de Estados Unidos, 376 U.S. 254, 1964, disponible en http://bit.ly/2xMBhGA. 
Corte Suprema de Estados Unidos en 1964, es bastante clarificador. Charney (2016: 184), al referirse a este caso, comenta que «cuando la carga de la prueba de la verdad recae en el querellado, éste tenderá a abstenerse de criticar a la autoridad si no es capaz de probar la veracidad de sus dichos en juicio, aun cuando se trate de hechos de serio interés público y que crea verdaderos e incluso cuando esos hechos sean, en efecto, verdaderos».

Este mismo caso, The New York Times con Sullivan, da inicio a la doctrina de la actual malice en Estados Unidos, la cual viene a equiparar el problema de la carga de la prueba, cuando la noticia revierte un interés público. Esta doctrina establece que cuando una publicación, a pesar de ser difamatoria, involucra a un funcionario público en razón del interés público que recae en su cargo, éste debe probar la intención maliciosa de la publicación y no darla por establecido por el hecho de ser falsa para incurrir en faltas penales (Wasserman, 2013).

En Argentina la jurisprudencia ha recogido esta teoría, denominándola como la doctrina de la real malicia, por la cual

la prensa puede encontrar su amparo cuando se informe sobre cuestiones públicas, sus funcionarios, figuras públicas o particulares involucrados en ella, aunque la noticia tuviera expresiones falsas o inexactas, siempre y cuando aquella persona que se considere afectada por alguna noticia con semejante contenido no llegue a demostrar que el periodista conocía la falsedad de la noticia y haya obrado con real malicia con el propósito de injuriar o calumniar (Stoppani, 2007: 15).

Los países anglosajones, a través de su actividad jurisprudencial, han avanzado en establecer criterios para un balance más efectivo entre el derecho a la honra y el ejercicio de la libertad de expresión, dejando en evidencia que la exceptio veritatis no es una garantía suficiente para alcanzar este objetivo. El hecho de que las decisiones jurisprudenciales tengan el efecto de ser vinculantes como precedentes en el sistema del Common Law hace que éstas tengan el efecto de disminuir el nivel de incertidumbre relativa a la resolución de estos casos. Por el contrario, la poca sofisticación de nuestra legislación en la materia, unido a la dispersión de la jurisprudencia, han tenido el efecto de entregar poca predictibilidad y seguridad jurídica a la resolución casos en que existe un conflicto de ponderación entre el derecho a la honra y la libertad de expresión.

\section{Distintas hipótesis de vulneración relativas al efecto inhibitorio}

Como vimos anteriormente, la premisa subyacente a la existencia de un efecto inhibitorio es que los individuos se verán disuadidos de manera más o menos frecuente de ejercer su derecho a la libertad de expresión de forma legítima por miedo a una repercusión jurídica contenida en una normativa relativa a una materia distinta a 
la regulación de la libertad de expresión; en nuestro caso de estudio, en el delito de injuria y calumnia.

En un mundo ideal $-\mathrm{y}$ habiéndose subsanado las carencias legislativas en los tipos penales antes descritos- los individuos deberían poder operar con la certeza jurídica de que sus actos se encuentran fuera de la descripción típica de la injuria y la calumnia. Por tanto, deberían actuar con tranquilidad de que están actuando conforme a derecho y no serán perseguidos penalmente por su actuar.

Sin embargo, no resulta difícil darse cuenta de que existen diferencias evidentes entre este modelo ideal y la realidad. La principal diferencia entre cómo opera el sistema legal a nivel abstracto y la maquinaria del sistema jurídico en la práctica, es que este último suele cometer errores (Schauer, 1978: 694).

En efecto, es la posibilidad de ocurrencia de estos errores y la consecuente incertidumbre que esto genera lo que habilita la existencia de un efecto inhibitorio en materia de libertad de expresión. Esta incertidumbre puede producirse por varios factores: es posible que exista una imposibilidad de probar un hecho, que la interpretación de dichos hechos se haga a través de un sesgo del sentenciador, e incluso - si existe consenso en la interpretación de los hechos- existe la posibilidad de que el derecho sea aplicado de forma errónea. De lo anterior, se colige que existe una incerteza inherente a la litigación que no hace posible predecir su resultado de forma satisfactoria.

En este sentido, coincidimos con la postura de Charney, respecto a que los efectos negativos de la tipificación de la injuria y la calumnia no pueden ser subsanados de forma completamente satisfactoria a través de la consagración de una exceptio veritatis robusta y rigurosa en los tipos penales en cuestión. Pero disentimos, en parte, de que la solución sea la prevista en los sistemas anglosajones, en los cuales el imputado por injurias puede demostrar su inocencia incluso si la información de interés público publicada sea falsa si: i) prueba su diligencia en la forma de recabar la información y un trabajo periodístico responsable en el caso británico o ii) si el demandado actuó de buena fe o ante la duda tomó las medidas necesarias para verificarla, en el caso norteamericano (Charney, 2016: 187). Esta concepción proviene de una aproximación a los problemas jurídicos que se limita al análisis de la legislación y la jurisprudencia, pero que no toma en consideración otros factores sociales, políticos y económicos que estas tipificaciones producen en el ejercicio concreto de la libertad de expresión en general, y en el ejercicio del periodismo en particular.

Estos factores van desde el estigma social de haber sido condenado penalmente, o incluso solo de haber sido acusado públicamente y haber sido procesado ante la justicia, a la posible afectación de la reputación profesional y la imposición de ciertas inhabilidades. A su vez, esta afectación reputacional puede tener consecuencias económicas, como la pérdida del empleo o la dificultad de obtener uno en el futuro. Asimismo, los eventuales costos procesales en la litigación pueden servir de disuasivo para medios de comunicación afianzados, pero afecta desproporcionadamente a 
medios de comunicación o individuos sin filiación institucional, que pueden no tener los medios económicos para incurrir en gastos de defensa judicial.

En este sentido, y teniendo en consideración la falta de certeza inherente a la litigación, el solo hecho de que la injuria y la calumnia estén sancionadas con penas criminales puede resultar en una disuasión suficiente para los agentes que de otra forma ejercerían de manera legítima su derecho a expresarse. Siguiendo lo señalado por Schauer (1978: 697),

la posibilidad de ser encarcelado, sumado con el estigma y las inhabilidades que acompañan a la sentencia criminal, la mayoría de las veces harán que el individuo vea la pena criminal como más dañina que la sanción civil. De esta forma, el miedo a un veredicto erróneo aumentará cuando la sanción es criminal, aun cuando la probabilidad de una determinación judicial incorrecta se mantenga constante.

En otras palabras, si bien el necesario perfeccionamiento de los tipos penales de la injuria y la calumnia constituye un paso necesario para combatir los efectos perversos más inmediatos producidos por su deficiente redacción, lo cierto es que se seguirá produciendo un efecto inhibitorio sobre la libertad de expresión en la medida en que los agentes vean como una posibilidad factible la de ser perseguidos criminalmente por sus dichos. De esta forma, resulta indispensable que el legislador despenalice estas conductas, optando por un sistema de indemnización civil por la comisión de estas conductas atentatorias a la honra, como existe en los países anglosajones. ${ }^{21}$

Incluso una mera sanción civil puede resultar en un efecto inhibitorio a la libertad de expresión, en la medida que ésta resulte desproporcionada. En este sentido, la Corte Interamericana de Derechos Humanos sostuvo que

el temor a una sanción civil desproporcionada puede ser a todas luces tan o más intimidante e inhibidor para el ejercicio de la libertad de expresión que una sanción penal, en tanto tiene la potencialidad de comprometer la vida personal y familiar de quien denuncia o publica información sobre un funcionario público, con el resultado evidente y disvalioso de autocensura, tanto para el afectado como para otros potenciales críticos de la actuación de un servidor público. ${ }^{22}$

21. En Estados Unidos, desde la dictación del emblemático caso The New York Times con Sullivan por parte de la Corte Suprema, el número de estados con leyes de difamación con sanciones penales se ha reducido a quince, y aun en dichos estados el número de persecuciones penales bajo esta figura se ha reducido a un promedio de tres al año (Robinson, 2007). Del mismo modo, en Inglaterra la decisión del caso Reynolds con Times Newspapers y otros, de 1999, sentó las bases para la actual Defamation Act de 2013, bajo la cual el afectado solo puede solicitar una indemnización civil por los daños causados.

22. Sentencia del caso Fontevecchia y D'Amico con Argentina, Corte Interamericana de Derechos Humanos, serie C núm. 237, 29 de noviembre de 2011, párrafo 74, disponible en http://bit.ly/30wkFPO (citado en Charney, 2016). 
También es necesario tener en consideración que el nivel de daño al que se expone el agente no solo considera las sanciones civiles y criminales que pueden resultar de la litigación, sino que también los efectos que éstas puedan causar que no son necesariamente de carácter jurídico. Estos efectos extrajurídicos pueden aumentar el efecto disuasivo de la eventual decisión errónea, en la medida que pueden producir resultados indeseados como la pérdida de amistades, daño en la reputación profesional y social, pérdida del empleo e incapacidad para obtener uno nuevo, etcétera (Schauer, 1978: 697).

Otro elemento que escapa al mero estudio de los tipos penales y la jurisprudencia es la existencia de comportamiento estratégico por parte de los agentes que se sienten afectados por expresiones u opiniones que consideran atentatorios a su derecho a la honra. De esta forma, la amenaza de la interposición de una querella por injuria o calumnia no necesariamente debe materializarse para resultar efectiva; la sola amenaza de su interposición puede ser suficiente para lograr que otro se abstenga de ejercer su derecho a expresarse.

Del mismo modo, cuando dicha querella es efectivamente interpuesta, no necesariamente debe llevarse hasta su conclusión procesal, su mera interposición puede hacer las veces de amenaza. Esta tendencia es descrita por Cabalin-Quijada y LagosLira (2009: 49) como

una estrategia que intimida al afectado directo, así como a otros periodistas o medios para abordar temas o actores que reaccionan por esta vía ante informaciones críticas [así como] estrategias de hostigamiento judicial por parte de gobiernos, locales o nacionales, destinadas a silenciar voces críticas. En definitiva, la vía judicial es una herramienta efectiva para intimidar e inhibir a periodistas y medios de incorporar contenidos que pueden resultar incómodos para poderes formales o de facto.

Otro elemento para considerar es la motivación del individuo o medio de comunicación a la hora de informar o ejercer su derecho a expresar su opinión. Para un individuo profundamente comprometido con una causa en particular, el nivel de disuasión necesario para que opere la autocensura producida por el efecto inhibitorio será más bien alto. Sin embargo, la regla general es que la información y la opinión sean dadas a conocer a la población por medios de comunicación que operen a través de una motivación comercial más que en un compromiso personal en la diseminación de ideas específicas. ${ }^{23}$ En este sentido, queda claro que la disuasión de la que pueden ser víctima los agentes no solo pasa por la gravedad de la sanción, sino también por el cálculo de costo/beneficio económico que estos agentes pueden hacer. En otras palabras, muchas veces un ataque al bolsillo puede resultar igual o más disuasivo que la amenaza de una sanción penal.

23. Para Schauer (1978) este incentivo puede incluso expresarse como una fórmula, a saber: disuasión = aversión al riesgo [(probabilidad de castigo x gravedad del castigo $)$ - beneficio esperado)]. 
Lo anterior resulta particularmente problemático si tenemos en consideración que esta variable económica afecta desproporcionadamente a los individuos sin filiación institucional y aquellos medios de menor capacidad económica, de carácter regional, alternativos o comunitarios, los que muchas veces son los encargados de permitir la existencia de discursos críticos o subalternos (Etling, Roberts y Faris, 2014). Para estos medios de menor capacidad económica, la mera amenaza de una litigación judicial, con los costos que acarrea la litigación ${ }^{24}$ y la incertidumbre de su resultado, producirá en un efecto inhibitorio que podría disuadir de publicar o dar a conocer información u opiniones amparadas en el ejercicio de la libertad de expresión. Esto es particularmente preocupante para un país como Chile, que cuenta con niveles importantes de concentración económica de los medios de comunicación. De acuerdo con un informe elaborado por el Observatorio Latinoamericano de Medios y Convergencia (Observacom), la concentración de los medios en Chile alcanza el $75 \%$ en el caso de la prensa escrita y el $89 \%$ en la televisión abierta. ${ }^{25}$

Por último, una forma más sutil - pero no por ello menos perniciosa- de autocensura corresponde a la excesiva cautela con la que los ciudadanos y periodistas pueden sentirse obligados a utilizar al momento de cubrir ciertos hechos o dar a conocer sus opiniones. En efecto, los individuos se ven conflictuados no solo por la incertidumbre de una eventual decisión judicial, sino también por la propia incertidumbre de que su conducta se apega a lo descrito por la norma.

Esta excesiva cautela producida por el miedo a una persecución judicial puede dar pie a que los individuos no expresen discursos legítimos del modo en que mejor estimen conveniente, sino que solo lo hagan hasta el punto en el que sientan la seguridad de no arriesgarse a un castigo ulterior. En el caso de la prensa, puede dar pie a un ambiente periodístico pacato y poco atrevido, incapaz de aventurarse en donde es más necesaria su labor: en situaciones que incomoden al poder político, económico y cultural. Lo anterior daría como resultado un debate público empobrecido y amainado, lo que necesariamente va de la mano con el debilitamiento de nuestro sistema democrático.

\section{Conclusión}

El presente artículo ha buscado dar cuenta de cómo la deficiente tipificación de los delitos de injuria y calumnia ha inclinado la balanza en la protección de derechos

24. A este respecto, Mac-Clure (2007: 134) señala: «Los costos de litigación para los medios también son altos; las víctimas de difamación demandan pese a no tener muchas perspectivas de ganar el juicio, motivados por restablecer su buena reputación. Estos costos de litigación son más problemáticos todavía cuando el demandado es un medio de comunicación pequeño o un ciudadano común».

25. Natalia Figueroa, "Concentración de medios amenaza la democracia y libertad de expresión», Radio Universidad de Chile, 5 de octubre de 2016, disponible en http://bit.ly/2XOqLcR. 
fundamentales a favor de la honra y en detrimento del derecho a la libertad de expresión. Sin embargo, una investigación más acuciosa y de carácter empírica es necesaria para levantar evidencia respecto de cómo efectivamente la existencia de estas figuras penales afecta el derecho a expresión de los individuos y medios de prensa.

Del estudio de las disposiciones mencionadas y la doctrina en torno al efecto inhibitorio es posible concluir que, en la medida en que pese sobre los individuos la posibilidad de que sus dichos u opiniones habiliten al afectado para perseguir criminalmente su responsabilidad ante tribunales, existe la amenaza de que esta posibilidad opere como disuasión y genere un efecto de autocensura.

Si bien la reforma constitucional del año 2005 avanzó en la materia a través de la derogación del inciso segundo del artículo 19 numeral 4, lo cierto es que aún es necesaria una modificación sustantiva de los tipos penales de la injuria y la calumnia para asegurar que el ejercicio de la libertad de expresión no se vea arbitrariamente amenazado por la utilización antojadiza o estratégica de estas figuras penales. Esta reforma debe tener como un punto de partida un entendimiento más sofisticado de los bienes jurídicos en juego, haciéndolos consistentes con el régimen vigente de derechos fundamentales en Chile, incluyendo las obligaciones internacionales del país en materia de derechos humanos.

En este sentido, resulta indispensable otorgar a todas las personas - no solo a los medios sociales de comunicación - la capacidad de hacer uso de la exceptio veritatis, para proteger las distintas formas de expresión que versen sobre asuntos de interés público. La posibilidad de utilizar la exceptio veritatis por parte de los ciudadanos comunes y corrientes no debería estar circunscrita a cuando las expresiones se refieran a un funcionario público, sino que respecto de cualquier figura pública o hecho de trascendencia pública.

Sin embargo, la existencia de herramientas robustas para la defensa judicial no es suficiente, el análisis de los elementos paralegales que dan pie a la existencia del efecto inhibitorio muestra que éste también puede tener lugar cuando la legislación ofrece herramientas razonables a los imputados. La afectación a la libertad de expresión puede, de esta forma, producirse a través de mecanismos como la incertidumbre en el resultado de las sentencias judiciales, el miedo fundado a consecuencias extrajurídicas de la sentencia o el cálculo de costo/beneficio que los agentes pueden hacer tomando en consideración el costo económico de la litigación.

Si bien este fenómeno no puede ser eliminado del todo, su necesaria atenuación hace necesaria la derogación de los delitos de injuria y calumnia del Código Penal, y su reemplazo por un sistema de indemnización civil. ${ }^{26}$ De lo contrario, seguirá pen-

26. Un ejemplo para seguir es México, país que en el año 2007 derogó los delitos de injurias, difamación y calumnia y los reemplazó por supuestos de responsabilidad ulterior de carácter civil para la reparación del daño y la incorporación del derecho a la rectificación (CELE, 2018: 9). 
diendo sobre el periodismo chileno la espada de Damocles de la persecución criminal del ejercicio legítimo de su profesión.

Solo así podrá Chile avanzar en evitar que la autocensura producida por el efecto inhibitorio vulnere el derecho a la libertad de expresión de los individuos que han dejado de ejercerla por miedo a una represalia judicial y en la obligación del Estado de establecer un marco institucional que promueva la libertad de expresión, el libre intercambio de ideas y opiniones y un debate público robusto que fortalezca nuestro sistema democrático.

\section{Referencias}

ANSUÁtegui, Francisco (1992). «Orígenes doctrinales de la libertada de expresión». Tesis doctoral, Universidad Carlos III de Madrid, España. Disponible en http:// bit.ly/2XKjLNS.

Cabalin-Quijada, Cristian y Claudia Lagos-Lira (2009). «Libertad de expresión y periodismo en Chile: Presiones y mordazas». Palabra Clave, 12 (1): 37-59. Disponible en http://bit.ly/2XKl2Vf.

CaHn, Edmond (1956). «The firstness of the First Amendment». The Yale Law Journal, 65 (4): 464-481. DOI: $10.2307 / 793983$.

CELE, Centro de Estudios en Libertad de Expresión y Acceso a la Información (2018). Tendencias en libertad de expresión en México. Buenos Aires: Universidad de Palermo. Disponible en http://bit.ly/2JIiYYM.

ChARNEY, John (2016). «La tensión entre la libertad de emitir opinión y la de informar y la honra de las personas: Importancia y límites de la exceptio veritatis». Revista de Derecho (Valdivia), 29 (2): 175-193. DOI: 10.4067/So718-09502016000200008.

$\mathrm{CIDH}$, Comisión Interamericana de Derechos Humanos (2017). Informe anual de la Comisión Interamericana de Derechos Humanos. Volumen 2. OEA/Ser.L/V/II, documento 22/17. Disponible en http://bit.ly/2JDMJdq.

Covarrubias Cuevas, Ignacio (2005). «Notas críticas a la figura del "personaje público" como criterio legitimador para la intromisión en la vida privada de las personas». Estudios Constitucionales, 3 (2): 163-197. Disponible en http://bit. ly/2XNo7kg.

-. (2015). «La vida privada de los funcionarios públicos frente a dos derechos: El acceso a la información pública y la libertad de expresión. (Algunos criterios empleados por la jurisprudencia chilena y comparada y su importancia relativa)». Ius et Praxis, 21 (1): 217-270. DOI: 10.4067/So718-00122015000100007.

Doherty, Michael (2007). «Politicians as a species of "public figure" and the right to privacy». Humanitas Journal of European Studies, 1 (1): 35-55. Disponible en http:// bit.ly/2 $\mathrm{ScOO}_{3} \mathrm{C}$. 
EtLING, Bruce, Hal Roberts y Robert Faris (2014). «Blogs as an alternative public sphere: The role of blogs, mainstream media, and TV in Russia's media ecology». Berkman Center Research Publication, 2014-8: 1-51. DOI: 10.2139/ssrn.2427932.

Fuentes, María Fernanda (2011). «El derecho a la honra como límite a la libertad de información hasta el momento de la acusación penal». Revista de Derecho (Valparaíso), 37: 547-564. DOI: 10.4067/So718-68512011000200014.

Gandolfo, Pedro (1994). «¿Licencia para informar?». Estudios Públicos, 53: 263-288. Disponible en http://bit.ly/2Gbh2XL.

Garrido Montt, Mario (1998). Derecho penal: Parte general. Tomo 3. Santiago: Jurídica de Chile.

Labatut Glena, Gustavo (1977). Derecho Penal: Parte especial. Santiago: Jurídica de Chile.

Mac-Clure, Lucas (2007). «Práctica judicial, derecho a la honra y libertad de expresión: Un análisis de la jurisprudencia constitucional chilena». Memoria para optar al grado de licenciado en Ciencias Jurídicas y Sociales. Universidad de Chile.

Nieves, María (2016). «Alcance y límites de la defensa de la libertad de expresión en la teoría política de Baruch Spinoza». Historia Constitucional, 17: 15-44. DOI: 10.17811/hc.voi17.450.

Nogueira, Héctor (2003). Teoría y dogmática de los derechos fundamentales. Ciudad de México: Editorial Nacional Autónoma de México.

-. (2004). «Pautas para superar las tensiones entre los derechos a la libertad de opinión e información y los derechos a la honra y la vida privada». Revista de Derecho (Valdivia), 17: 139-160. DOI: 10.4067/So718-09502004000200006.

Nogueira Alcalá, Humberto (2002). El derecho a la libertad de opinión e información y sus límites. Santiago: Lexis Nexis.

OEA, Organización de los Estados Americanos (2009). «Marco jurídico interamericano sobre el derecho a la libertad de expresión». Relatoría Especial para la Libertad de Expresión. OEA/Ser.L/V/II CIDH/RELE/INF. 2/o9. Disponible en http:// bit.ly/2xK81R9.

Politoff, Sergio, Jean Pierre Matus y María Cecilia Ramírez (2003). Lecciones de derecho penal chileno: Parte general. Santiago: Jurídica de Chile.

Robinson, Eric (2007). «Criminal libel and the internet». Journal of Internet Law, 11(4): 1-19.

SchaUer, Frederick (1978). «Fear, risk and the First Amendment: Unraveling the chilling effect». Boston University Law Review, 58: 685-732. Disponible en http://bit. ly/2XJmAiP.

StopanNi, Hernán (2007). «Restricciones jurídicas y materiales, legítimas e ilegítimas, a la libertad de prensa». Tesis para la Universidad Abierta Interamericana, Argentina. Disponible en http://bit.ly/2NVcc7m. 
Vega Zamora, Hugo (2012). «El derecho a la libertad de expresión: ¿Una limitante al poder estatal?». Revista de Derecho (Coquimbo), 19 (2): 355-369. DOI: 10.4067/ So718-97532012000200012.

Wasserman, Howard (2013). «A jurisdictional perspective on New York Times v. Sullivan». Northwestern University Law Review, 107 (2): 901-914. Disponible en http://bit.ly/2XN3WG6.

\section{Sobre los autores}

Pablo Viollier Bonvin es abogado. Licenciado en Ciencias Jurídicas y Sociales de la Universidad de Chile. Actualmente es analista de políticas públicas de la ONG Derechos Digitales. Su correo electrónico es pablo@derechosdigitales.org.

Matías Salinas Salgado es abogado. Licenciado en Ciencias Jurídicas y Sociales de la Universidad de Chile. Es investigador de la Unidad de Derechos Humanos de la Corte de Apelaciones de San Miguel. Su correo electrónico es matias.salinas@ gmail.com. 
